\title{
Textual coherence in EFL Student Writing
}

\author{
Nadia Hellalet \\ Mohammed V University Souissi, College of Education Sciences
}

\begin{abstract}
The study investigates EFL learners' use of coherence relations at three levels of language learning. A corpus of ninety essays was analyzed using rhetorical Structure Theory as a framework. The objective is to investigate the developmental aspect of coherence in the Moroccan EFL learners' writings. The MANOVA results reveal that the learners' proficiency level has a significant effect on their use of coherence relations. The use of cause, interpretation, justifies, condition, solutionhood, elaboration, purpose, evidence and evaluation increases as the learners develop higher level of language proficiency. However, the relations that are referred to as macro-relations and that affect writing quality such as elaboration, evaluation, evidence and sequence are found only in third year college students.This reflects these students' ability to support and elaborate their ideas.Students at lower levels, however, need to develop the ability to use these macro relations, since they are the main contributors to global coherence.
\end{abstract}

Key words: Coherence, Rhetorical Structure Theory, Writing.

\section{Introduction}

This study is based on practical pedagogical problems that Moroccan university students encounter in writing. One of the challenges EFL learners face is how to write coherent texts that can be understood by their readers. Actually, coherence was defined differently by different researchers. It was introduced by some researchers as reader-based. That is, it is achieved when the reader has a certain background knowledge that enables him/her to understand the text at hand. Other researchers believe that it is achieved when the text contain the linguistic features that are necessary to facilitate comprehension. Between these two sides comes Rhetorical Structure Theory that is a theory of text analysis that takes the reader into consideration. It is adopted in this study because it provides an explicit account of the rhetorical relations in text. These relations are counted using the statistical package of social sciences (SPSS).

\section{Coherence}

\section{Background}

Coherence is a complex concept, which has been subject to controversy among discourse analysts. Accordingly, two approaches to the term are distinguished, namely text-based and reader-based coherence.

\section{Textual coherence}

Coherence, according to the text-based approach, refers to the semantic unity of text that is achieved by means of cohesive ties (Halliday and Hasan, 1976). That is, coherence is defined in terms of the linguistic features in the text that distinguish a text from a cluster of sentences. $\mathrm{H} \& \mathrm{H}$ use the word texture to refer to it. "If a passage of English containing more than one sentence is perceived as a text, there will be certain linguistic features present in that passage which can be identified as contributing to its total unity and giving it texture." (pp2)

This approach is criticized by many researchers who think that coherence is achieved through the relationships among sentences and ideas in a text that contribute to its rhetorical unity. Respectively, analyzing the underlying propositional units in text is more revealing than looking for the cohesive ties. For a text to be coherent it should meet the following criteria: cohesion, organization (the orderly, systematic presentation of information) and register, which refers to the situational consistency (Moe, 1979:18). In this respect, writers should present information in a well-organized way, and use the appropriate cohesive ties to create coherent texts and facilitate comprehension. Fahnestock (1983), accordingly, defines coherence as the quality enabling a reader to get meaning from a text thanks to the paragraph organization which follows some model of development. A text may be described as coherent when its reader is able to move from one clause to the other without losing the meaning. So it is the writer's responsibility to bridge the gap between adjacent sentences through transition words, which may be marked or unmarked.

\section{Reader-based coherence}

As for the reader-based approach, coherence is achieved through the successful interaction between the reader and the text (Rumelhart, 1977; Widdowson 1978; Carrel 1982, 1984). That is, the reader is able to 
reconstruct the writer's meaning on the basis of the information and strategies he brings to the comprehension process and the text's cues. Coherence results from the reader's text knowledge and word knowledge (De Beaugrande and Dressler, 1981; Morgan and Sellner, 1980; Webber, 1980)

\section{Schema theoretical view of cohesion and coherence Schema theory}

Schema theory is an approach to information processing coming from research in cognitive science. Rumelhart (1981) defines schema as:

the fundamental elements upon which all information processing depends. schema[s] are employed in the process of interpreting sensory data, ... in retrieving information from memory, in organizing actions, in determining goals, ... in allocating resources, and generally in guiding the flow of processing in the system. ... A schema ... is a data structure for representing the generic concepts stored in memory. ... Schemas represent knowledge about ... objects, situations, events, sequences of events, actions, and sequences of actions (pp. 33-34).

\section{Schema theoretical view of cohesion}

Cohesion, according to schema theory, is a result rather than a cause of coherence. It derives from the reader's text knowledge and world knowledge (De Beaugrande and Dressler, 1981; Carrell, 1982; Morgan and Sellner, 1980) in the content which has linguistic consequences; meaning that the use of cohesive ties is an effect rather than a cause. For Morgan and Sellner (1980)

"The source of coherence would lie in the content, and the repeated occurrences of certain words would be the consequence of content coherence, not something that was a source of coherence." (pp: 179)

Tierney and Mosenthal (1981) pointed out that cohesion is causally unrelated to text's coherence and that the topic or content has an effect on the options a writer has for using cohesive devices.

\section{Schema theoretical view of coherence}

Coherence, according to the schema-theory, is achieved by means of a successful interaction between the reader and the text (Carrell 1982, 1984, 1985; Rumelhart, 1977). In other words, the reader gets meaning from the text according to the schemata he/she activates and the expectations he/she has. The writer and the reader are expected to share content and formal schemata which lead to the coherence of the text. In other words, there is a coherence contract between the reader and writer that enables the reader to reconstruct "a coherent real world scene" (Fillmore, 1977). These schemata and expectations are modified until they become consistent with the text's structure or content. (Carrell, 1983). The same view is adopted by De Beaugrande\& Dressler (1981), who point out that "a text does not make sense by itself, rather by the interaction of textpresented knowledge with people stored knowledge of the world." (p:6). In this respect, a text is made of a continuity of senses which contribute to its coherence.

Carrell (1982) criticizes the notion of cohesion as a measure of coherence. As she points out, "If a reader does not have, or fails to access, the appropriate schema underlying the text, all the cohesive ties in the world won't help that text cohere for that reader."(p:485). She considers cohesion theory as far from being the solution to ESL reading and writing problems since the textual analysis techniques are not revealing when it comes to the assessment of coherence. In this regard, teaching cohesion does not guarantee the coherence of text because cohesion is the effect of the coherence of the content not the other way round. Carrell believes that cohesion studies are necessary, but they are not sufficient. Broader and more powerful theories, which involve the reader, the writer and the text, are needed. Carrell's view was criticized by Rankin who pointed out that Carrell expanded the concept of coherence at the expanse of cohesion theory and text analysis: “... she deflates the importance of text analysis generally and the value of cohesion specifically, although these linguistic notions provide explicit entrance into the processing of written text as well as to its production" Carrell (1984) responds to this criticism through demonstrating the importance of an interactive view of text analysis, refuting Rankin's assumption active imitation can improve acquisition; meaning that it can help learners produce texts that are not only cohesive but also coherent. She adopts with De Beaugrande and Dressler's definition of text as an interactive, communicative occurrence, of which cohesion is only one element. She recognizes the importance of enriching the learners' vocabulary repertoire and their background schemata to enable them produce and process texts adequately: "We might also profitably focus on vocabulary development and the enrichment of the student's background schemata to which the lexical items refer" (p166)

\section{Rhetorical structure theory}

Coherence, according to RST, is defined as "the absence of non-sequiturs and gaps" (Mann, 1999). In other words, every part of a coherent text has some intended function or functions; that is, some plausible reason 
for its presence that is evident to the reader. Yet, if there are some parts that are somehow missing, this will affect the text's coherence.

Rhetorical Structure theory is used in this study as a framework to assess coherence in the students'writings. This theory accounts for the text structure above the clause level. It deals with text as a medium of communication that is organized hierarchically. As Mann and Thompson (1988) put it, it "provides a general way to describe the relations among clauses in a text, whether or not are grammatically or lexically signaled" (p244). It is used to describe a variety of text types, including narrative discourse. In fact, it is useful in the study of text coherence because it provides a framework for investigating relational propositions, which coherence partially depends on. In addition, rhetorical structure theory is a functional account of the text as a whole. It analyzes text in terms of the effect the writer intends to get on the reader. Therefore, its main focus is the relations that exist among clauses rather than the explicit discourse markers. Rhetorical structure theory will be adopted in this study because it gives a more objective analysis of coherence relations and a visual representation of these relations.

\section{Subjects}

\section{The Study}

The participants in this study are first-year and third-year university students. They are from the same linguistic background. Students in Morocco study Arabic and French at primary school, middle school, and high school, and start learning English at grade nine when they take a two-hour class every week in which they are introduced to some basics of grammar, vocabulary, and functions. At grade ten, the number of hours devoted to learning English increases to four hours for literature students and three hours for science students. During the three years of language teaching in high school the focus is on teaching grammar, reading comprehension, and writing, especially in the twelfth grade when students are expected to take a final exam in English. The exam is written; hence the teachers' focus is on instruction in writing. Even the quizzes and tests administered to assess the students' learning are written. If students want to join the English department when they get their high school diploma, they have to take an entrance test which determines their proficiency in the language. They have to take an oral test first, but if they do not perform well on it, they have to take a written one.

\section{Data collection and sampling}

The data collection took place in May 2012 in Mohamed V University in Rabat and ChoaibDokkali University in El Jadida, both in Morocco. The instrument used for analysis in this study is the students' essays. Eighty students participated in the study. They were given an argumentative topic to write on: Some people prefer to marry when they are young, while others prefer to wait until they are older to marry. Make a case for which you think is better and why. The writing process took place in the classroom in one hour; students could not use dictionaries or other reference books. Before writing, students were given fifteen minutes to discuss their ideas in groups to control for any variation that might arise as a result of familiarity with the topic. The essays were scored holistically by two teachers and the researcher, and given grades of 1 to 3 out of 10 for the weak ones, 4 to 5 out of 10 for the averages ones, and 6 to 7.5 out of 10 for the strong ones. Twenty essays were selected randomly, ten from those that were rated high and ten from those that were rated low, thereby creating two proficiency levels.

\section{Rhetorical structure analysis}

The method of analysis used to investigate coherence relations in the students' essays is RS analysis. Students 'essays are broken down into Rhetorical Structure units, which correspond to clauses. But, sometimes the sentences in the essay may contain more than one unit. In this respect, they may be divided into units. The relations among these units are either signaled or unsignaled. They are counted and processed using SPSS.

\section{Statistical Analysis}

The main objective is to find out the effect of grade level on the learners use of coherence relations in their essays. The MANOVA technique is required in this respect to achieve this objective. 


\section{Results}

Table 1: MANOVA Results of Coherence Relations in the Writings of the Three Level Groups:

\begin{tabular}{|c|c|c|c|c|c|}
\hline & First Year & Second Year & Third Year & & \\
\hline Variables & Mean & Mean & Mean & $\mathrm{F}$. & Sig \\
\hline Joint & 2.70 & 2.35 & 2.80 & 0.397 & 0.67 \\
\hline Restatement & 0.45 & 0.70 & 0.60 & 0.541 & 0.58 \\
\hline Contrast & 1.05 & 1.10 & 1.35 & 1.273 & 0.28 \\
\hline Cause & 0.45 & 1.40 & 1.10 & 9.597 & 0.00 \\
\hline Non-related clauses & 0.95 & 0.50 & .00 & 11.447 & 0.00 \\
\hline Result & 0.75 & 0.60 & 2.05 & 0.916 & 0.40 \\
\hline Interpretation & .00 & .00 & 0.40 & 22.066 & 0.00 \\
\hline Justify & 0.35 & 0.80 & 0.80 & 4.745 & 0.01 \\
\hline Condition & 0.15 & 0.40 & 0.50 & 6.045 & 0.004 \\
\hline Solutionhood & 0.25 & 0.00 & 0.50 & 18.142 & 0.00 \\
\hline Elaboration & 0.55 & 2.20 & 3.35 & 3.498 & 0.03 \\
\hline Purpose & 0.20 & 0.45 & 1.20 & 5.019 & 0.01 \\
\hline Evidence & 0.10 & 0.65 & 1.05 & 16.859 & 0.00 \\
\hline Sequence & 0.80 & 1.30 & 3.00 & 1.112 & 0.33 \\
\hline Evaluation & 0.01 & 0.45 & 0.75 & 20.053 & 0.00 \\
\hline
\end{tabular}

Table 1 is a summary of the univariate test for each of the dependent variables. It shows that there is no significant difference among the three level groups in terms of joint, restatement, contrast and sequence, $p>05$. Yet, the three groups differ with respect to cause $\mathrm{p}=.000$. First year students use less cause relations than second year students, with respective means of $0.45,1.40$. Third year students use less cause relations than second year students with a mean of 1.10. The three level groups also differ in terms of a category labeled in this study "nonrelated clauses". This category includes all the clauses in text which deviate from the text's rhetorical structure. The first level group uses more non-related clauses than the second group, $\mathrm{P}=.000$, with respective means of 0.95 and 0.50 . The third group seems to avoid the non-related clauses in their writings $(\mathrm{M}=.000)$. With respect to result relations, third year students seem to use more result relations $(M=0.75)$ than second year $(M=0.60)$, and third year students $(\mathrm{M}=2.05)$. Concerning interpretation, it is used only by third year students with a mean of (0.40).

Another interesting result is that second year and third year students use justify relations more often $(\mathrm{M}=0.80)$ than first year students $(\mathrm{M}=0.80)$. With respect to condition relations, it is more frequently used by third year students $(\mathrm{M}=0.15)$ than second year students $(0.40)$ and third year students $(0.50)$. As for elaboration, it is also used more frequently by third year students $(\mathrm{M}=3.35)$ than second year $(\mathrm{M}=2.20)$ and first year students $(\mathrm{M}=0.55)$. The same thing can be said about purpose.Third year students use more purpose relations $(\mathrm{M}=0.45)$ than second year students $(\mathrm{M}=0.45)$ and first year students $(0.20)$. Third year students also use more evidence relations $(\mathrm{M}=1.05)$ than second year $(\mathrm{M}=0.65)$ and third year students $(\mathrm{M}=0.10)$.

The three level groups also differ with respect to their use reason relations, which are less frequently used by first year and second year students, with respective means of $(M=0.00,0.10)$, than third year students $(M=0.30)$. Finally, third year students use more evaluation relations $(M=0.75)$ than first year $(M=0.01)$ and second year students $(\mathrm{M}=0.45)$.

\section{Discussion}

The results of the study reveal that the learners' level has a significant effect on the nature of coherence relations they use. However, when considering each type of coherence relations, no difference is noticed in the three groups with respect to their use of joint, contrast, sequence, restatement, and result. The first three relations are considered by Mann\&Thompson $(1986,1987,1988)$ as multi-nuclear relations. That is, they have more than one nucleus. The use of such relations is necessary to move from one idea to another. Yet, the overuse of such relations hinders the topic development. This implies that first year students rely on these relations because of their inability to support and explain their ideas.

Concerning the subjects' use of interpretation, condition, elaboration, purpose, evidence, reason, sequence, and evaluation, it increases as long as their proficiency level develops. Elaboration, evaluation, evidence and sequence are considered as macro relations or top level relations since they contribute to the global coherence of text. These relations are more frequently used by third year students, which imply that students at this level care more for creating global coherence in their writings.Accordingly, their essays are considered more coherent than first year and second year students' essays. This finding is compatible with Hilali's finding (2000) that high rated essays use more global relations.

\section{Conclusion}

Teaching coherence relations is of paramount importance to improve the students' writing quality. In this sense, the teacher may explicitly teach these relations and bring to the students awareness that each relation 
has a certain function in the paragraph and therefore in the whole essay. This may be achieved through providing students with natural texts and demonstrating the rhetorical patterns in these texts.

\section{References}

[1] M. Halliday, and R. Hasan. Cohesion in English (London: Longman, 1976). (1)

[2] A.J. Moe,Cohesion, coherence and the comprehension of text, Journal of Reading, 1979, 16-20. (1)

[3] J. Fahnestock, Semantic and textual coherence, College Composition and Communication, Vol. 34,No,4, 1983, 400-416. (1)

[4] H. Widdowson, Teaching language as communication (London, Oxford, 1978). (1)

[5] J. Morgan, M. Sellner, Discourse andl Linguistic theory, In R.J.Spiro et al. (Eds.), Theoretical Issues in Reading Comprehension. Hillside, NJ: Lawrence Erlbaum Associates, 1980. (2)

[6] R. De Beagrand, W. Dressler, Introduction to text linguistics (London, Longman 1981). (2)

[7] D. Rumelhart, Schemata: The building blocks of cognition, J.T.Gurthrie, (ed.), Comprehension and Teaching: Research Reviews, International Reading Association, 1981, 3-27. (2)

[8] P. Carrel, Cohesion is not coherence, TESOL Quarterly Vol. 16, No. 4, 1982, pp. 479-488. (2)

[9] P. Carrell, J.Eisterhold, Schema theory and ESL reading pedagogy, TESOL 17(4), 1983, 553-573. (2)

[10] P.Carrell, The effects of rhetorical organization on ESL readers, TESOL.Vol. 18, No. 3, 1984, 441-469. (2)

[11] W.C. Mann, and S. A. Thompson, Rhetorical Structure Theory: Toward a functional theory of text organization,Text8 (3), 1988, 243-281. (3)

[12] W.C.Mann. and S. A. Thompson, Relational Propositions In discourse, Discourse Processes 9, 1986: 57-90. (5)Hilali 